\title{
A School-Based Study of Adolescent All-Terrain Vehicle Exposure, Safety Behaviors, and Crash Experience
}

\author{
Charles A. Jennissen, $M D^{1,2}$ \\ Karisa K. Harland, $\mathrm{PbD}^{1,3}$ \\ Kristel Wetjen, $\mathrm{RN}^{2,4}$ \\ Jeffrey Peck, MS \\ Pam Hoogerwerf, BS ${ }^{2}$ \\ Gerene M. Denning, $\mathrm{PbD}^{1}$
}

'Department of Emergency Medicine, University of Iowa Carver College of Medicine, Iowa City, lowa

${ }^{2}$ University of lowa Children's Hospital, Iowa City, lowa

${ }^{3}$ University of Iowa Injury Prevention Research, Iowa City, lowa

${ }^{4}$ Division of Pediatric Surgery, University of Iowa Hospitals and Clinic, Iowa City, lowa

${ }^{5}$ US Army Corps of Engineers,

Washington, DC
Conflicts of interest: authors report none.

\section{CORRESPONDING AUTHOR}

Charles A. Jennissen, MD

Department of Emergency Medicine University of Iowa Carver College of Medicine 200 Hawkins Dr Iowa City, IA 52242

charles-jennissen@uiowa.edu

\begin{abstract}
PURPOSE More youth are killed every year in the United States in all-terrain vehicle (ATV) crashes than on bicycles, and since 2001, one-fifth of all ATV fatalities have involved victims aged 15 years or younger. Effectively preventing pediatric ATV-related deaths and injuries requires knowledge about youth riding practices. Our objective was to examine ATV use, crash prevalence, and riding behaviors among adolescent students in a rural state.
\end{abstract}

METHODS We administered a cross-sectional survey to 4,684 youths aged 11 to 16 years at 30 schools across lowa from November 2010 to April 2013. Descriptive and comparative analyses were performed.

RESULTS Regardless of rurality, at least $75 \%$ of students reported having been on an ATV, with $38 \%$ of those riding daily or weekly. Among ATV riders, 57\% had been in a crash. Most riders engaged in risky behaviors, including riding with passengers (92\%), on public roads (81\%), or without a helmet $(64 \%)$. Almost $60 \%$ reported engaging in all 3 behaviors; only $2 \%$ engaged in none. Multivariable modeling revealed male youth, students riding daily/weekly, and those reporting both riding on public roads and with passengers were 1.61 (95\% $\mathrm{Cl}, 1.36-1.91), 3.73(95 \% \mathrm{Cl}, 3.10-4.50)$, and $3.24(95 \% \mathrm{Cl}, 2.09-5.04)$ times more likely to report a crash, respectively.

CONCLUSIONS Three-fourths of youths surveyed were exposed to ATVs. The majority of riders had engaged in unsafe behaviors and experienced a crash. Given this widespread use and the potentially considerable morbidity of pediatric ATV crashes, prevention efforts, including anticipatory guidance by primary care clinicians serving families at risk, should be a higher priority.

Ann Fam Med 2014:310-316. doi: 10.1370/afm.1663.

\section{INTRODUCTION}

S ince 2001, youth aged 15 years and younger have represented nearly $30 \%$ of all US all-terrain vehicle (ATV)-related injuries and one-fifth of ATV-related deaths. ${ }^{1}$ In fact, more children are killed in the United States each year from ATVs than from bicycle crashes. ${ }^{2}$ Previous studies indicate that youth ATV operators have a 12 times greater risk of injury as compared with adults. ${ }^{3}$ This increased risk is likely due to a number of factors including physical and mental immaturity, lack of training and experience, riding adult-size machines, and a greater likelihood of being a passenger.-10

Despite the magnitude of the problem, there have been few published studies regarding ATV use, and these studies have mostly been limited to select rural and agricultural groups, ${ }^{7,11-14}$ or ATV-owning households. ${ }^{15}$ To our knowledge, this is the first study to provide epidemiology of ATV use and safety-related behaviors among a large cross-sectional sample of adolescents.

\section{METHODS}

\section{Study Design}

We recruited school districts to participate in an ATV safety education program through written or verbal communication with school nurses and 
administrators. Because previous studies showed that youth aged 12 to 15 years were at highest risk, ${ }^{8}$ we targeted classes with students in this age range. Schools participated from across the state, although most were from eastern lowa. This report includes all 30 participating schools from November 2010 through April 2013.

Before the safety program, an anonymous survey was electronically administered using TurningPoint technology (http://www.turningtechnologies.com/ polling-solutions/turningpoint). TurningPoint displays survey questions on PowerPoint slides with answers selected using a hand-held clicker (Table 1). All students in the scheduled classes completed the questionnaire, each as a unique respondent. The University of Iowa Institutional Review Board approved this study.

\section{Classification of Schools by Rurality}

School district rurality was determined using the zip code-based Rural Urban Commuting Area (RUCA) codes (http://depts.washington.edu/uwruca/rucaapprox.php). This classification takes into account the largest population center in the zip code area, as well as the proportion traveling to that center for work. Schools were coded into 4 RUCA categories: isolated rural, small rural, large rural, and urban. Because the large rural category had only 1 district, we combined large and small rural schools and designated this combined group as rural for analysis.

\section{Missing and Inconsistent Data}

A total of 364 students failed to answer the question "How often do you ride an ATV?" and were excluded from analysis, as we could not determine their ATV exposure. Those responding "never" to the question about riding frequency were categorized as unexposed all other answers placed the respondent in the exposed category. A total of 114 students categorized as exposed answered a subsequent safety behavior question with "Never been on an ATV"; this inconsistent response was treated as missing data.

\section{Data Analysis}

We performed all analyses using SAS software, version 9.3 (SAS Institute Inc). All comparisons of categorical variables were completed using the Pearson $\chi^{2}$ test. All $P$ values are for a 2 -sided test. We used hierarchical multivariable logistic regression analysis to calculate adjusted odds ratios and $95 \%$ CIs for dichotomous variables, after controlling for covariables and clustering within schools to control for a high correlation of ATV-related exposures within each school. Covariables for inclusion in the model were selected a priori based on previous research. Students with missing data for 1 or more model variables were not included in multivariable analysis.

\section{RESULTS}

\section{Exposure to ATVs}

Of the 4,684 students surveyed, $92 \%(4,320)$ responded to the question about ATV exposure. Table 2 shows their demographics. The proportion of female students and students aged 14 years or older was higher in the rural category, which included a large rural high school.

Seventy-seven percent of students reported having ridden on an ATV (Table 3). By school, this value ranged from $61 \%$ to $95 \%$. Exposure was higher for students from isolated rural schools as compared with other schools $(P<.001)$, but there was no difference between rural and urban schools. Among those exposed, 38\% reported they rode frequently, defined as daily or weekly. Although there was no difference in overall ATV exposure by sex, a higher proportion of male students reported riding almost daily $(P<.001)$.

\section{Riding Behaviors}

More than $90 \%$ of exposed students reported having been on a vehicle with multiple riders (Table 3), with a higher proportion seen for female students relative to male peers $(P<.001)$. More than $80 \%$ of exposed students reported riding on public roads, with no differences found by sex or rurality. The rate of regular helmet use (signified by a response of always or almost always) among students was only $17 \%$, and $64 \%$

\section{Table 1. Survey Questions and Response Options} Probing ATV Exposure and Riding Behavior

\begin{tabular}{|c|c|}
\hline Question & Response Options \\
\hline Q1. How old are you (years)? & - \\
\hline \multirow[t]{2}{*}{ Q2. What is your gender? } & Male \\
\hline & Female \\
\hline \multirow{5}{*}{$\begin{array}{l}\text { Q3. How often do you drive or ride } \\
\text { on an ATV? }\end{array}$} & Almost daily \\
\hline & About once a week \\
\hline & About once a month \\
\hline & Only a few times a year \\
\hline & Never \\
\hline \multirow{3}{*}{$\begin{array}{l}\text { Q4. Have you ever been in an ATV } \\
\text { crash (rolled over, hit something, } \\
\text { fallen off)? }\end{array}$} & Yes \\
\hline & No \\
\hline & Never been on an ATV \\
\hline \multirow{3}{*}{$\begin{array}{l}\text { Q5. Have you ever ridden or driven } \\
\text { an ATV with more than } 1 \text { person } \\
\text { on the ATV? }\end{array}$} & Yes \\
\hline & No \\
\hline & Never been on an ATV \\
\hline \multirow{3}{*}{$\begin{array}{l}\text { Q6. Have you ever ridden or driven } \\
\text { an ATV on a public road? }\end{array}$} & Yes \\
\hline & No \\
\hline & Never been on an ATV \\
\hline \multirow{5}{*}{$\begin{array}{l}\text { Q7. How often do you wear a helmet } \\
\text { when riding an ATV? }\end{array}$} & Always or almost always \\
\hline & More than half the time \\
\hline & Less than half of the time \\
\hline & Never or almost never \\
\hline & Never been on an ATV \\
\hline
\end{tabular}


reported never or almost never wearing a helmet. Helmet use was lower among female students $(P<.001)$ and isolated rural students $(P<.001)$ as compared with their respective peers. Only $2 \%$ of riders reported having engaged in none of the 3 unsafe behaviors, while 58\% reported engaging in all 3 (Table 4 ).

\section{Experienced a Crash}

Fifty-seven percent of students reported having been in at least 1 ATV crash (Table 4). Larger proportions of male students $(P<.001)$ and students from isolated rural schools $(P=.01)$ reported having been in a crash, and the proportion increased with age $(P=.02)$

Table 2. Demographic Characteristics of Study Population

\begin{tabular}{lccccc}
\hline Characteristic & $\begin{array}{c}\text { All, } \\
\text { No. (\%) }\end{array}$ & $\begin{array}{c}\text { Isolated Rural, } \\
\text { No. (\%) }\end{array}$ & $\begin{array}{c}\text { Rural, } \\
\text { No. (\%) }\end{array}$ & $\begin{array}{c}\text { Urban, } \\
\text { No. (\%) }\end{array}$ & $\begin{array}{c}P \\
\text { Value }^{a}\end{array}$ \\
\hline $\begin{array}{l}\text { Total number } \\
\text { Sex }\end{array}$ & $4,684(100)$ & $1,554(33)$ & $1,834(39)$ & $1,296(28)$ & - \\
$\quad$ Male & $2,153(49)$ & $760(52)$ & $775(45)$ & $618(50)$ & .001 \\
Female & $2,255(51)$ & $710(48)$ & $929(55)$ & $616(50)$ & \\
Age, Y & & & & & \\
11 & $690(16)$ & $263(19)$ & $228(13)$ & $199(16)$ & $<.001$ \\
$12-13$ & $2,526(58)$ & $780(58)$ & $882(52)$ & $864(68)$ & \\
$14-15$ & $952(22)$ & $285(21)$ & $463(27)$ & $204(16)$ & \\
16 & $54(4)$ & $26(2)$ & $123(7)$ & $5(<1)$ & \\
\hline
\end{tabular}

Note: Column totals may not equal overall population totals because of missing or indeterminate responses. ${ }^{\mathrm{a}} \chi^{2}$ analysis for comparison of proportions.

\section{Multivariable Analysis}

Odds of ATV Exposure and Safety Behaviors

The likelihood of ATV exposure was 39\% higher for youths aged 16 years relative to youths aged 11 years and for students from isolated rural schools relative to peers from urban schools (Table 5). Male students were about $40 \%$ less likely than female peers to have ridden with or as passengers. Monthly and daily/weekly riders were 3.5 and 5.6 times more likely, respectively, to have ridden on public roads than those riding only a few times a year. Students from isolated rural schools were $26 \%$ less likely, and from rural schools $39 \%$ less likely, to regularly wear helmets, as compared with urban students. Monthly riders were $20 \%$ more likely to report helmet use than those riding only a few times a year, but there was no difference between the most and least frequent riders.

Odds of Having Crashed Male students were $61 \%$ more likely to report having been in a crash (Table 6). Riding monthly or daily/weekly increased the likelihood by 2 -fold and 3.7-fold, respectively, relative to riding a few times a year. Students who reported never riding with pas-

Table 3. ATV Exposure and Riding Behaviors $(\mathrm{N}=4,320)$

\begin{tabular}{|c|c|c|c|c|c|c|c|c|}
\hline Exposure/Behavior & $\begin{array}{c}\text { All, } \\
\text { No. (\%) }\end{array}$ & $\begin{array}{l}\text { Male, } \\
\text { No. (\%) }\end{array}$ & $\begin{array}{l}\text { Female, } \\
\text { No. (\%) }\end{array}$ & $\begin{array}{c}P \\
\text { Value }^{a}\end{array}$ & $\begin{array}{l}\text { Isolated Rural, } \\
\text { No. (\%) }\end{array}$ & $\begin{array}{l}\text { Rural, } \\
\text { No. (\%) }\end{array}$ & $\begin{array}{l}\text { Urban, } \\
\text { No. (\%) }\end{array}$ & $\begin{array}{c}P \\
\text { Value }^{a}\end{array}$ \\
\hline \multicolumn{9}{|l|}{ Exposed to ATVs } \\
\hline Yes & $3,344(77)$ & $1,620(79)$ & $1,626(76)$ & .095 & $1,196(82)$ & $1,267(75)$ & $881(76)$ & $<.001$ \\
\hline No & $976(23)$ & $442(21)$ & $502(24)$ & & $269(18)$ & $429(25)$ & $278(24)$ & \\
\hline \multicolumn{9}{|c|}{ How often do you drive or ride on an ATV? } \\
\hline Almost daily & $666(20)$ & $378(23)$ & $263(16)$ & $<.001$ & $274(23)$ & $221(17)$ & $171(20)$ & .005 \\
\hline About once a week & $606(18)$ & $301(19)$ & $289(18)$ & & $226(19)$ & $231(18)$ & $149(18)$ & \\
\hline About once a month & $636(19)$ & $276(17)$ & $341(21)$ & & $221(18)$ & $231(18)$ & $184(22)$ & \\
\hline Only a few times a year & $1,436(43)$ & $665(41)$ & $733(45)$ & & $475(40)$ & $584(46)$ & $337(40)$ & \\
\hline \multicolumn{9}{|c|}{ Have you ever ridden or driven an ATV with more than 1 person on the ATV? } \\
\hline Yes & $2,948(92)$ & $1,409(90)$ & $1,455(94)$ & $<.001$ & $1,086(92)$ & $1,065(91)$ & $797(93)$ & .19 \\
\hline No & $261(8)$ & $155(10)$ & $100(6)$ & & $89(8)$ & $109(9)$ & $63(7)$ & \\
\hline \multicolumn{9}{|c|}{ Have you ever ridden or driven an ATV on a public road? } \\
\hline Yes & $2,534(81)$ & $1,237(81)$ & $1,226(80)$ & .75 & $889(82)$ & $952(79)$ & $693(81)$ & .096 \\
\hline No & $604(19)$ & $292(19)$ & $298(20)$ & & $191(18)$ & $255(21)$ & $158(19)$ & \\
\hline \multicolumn{9}{|c|}{ How often do you wear a helmet when riding an ATV? } \\
\hline Always, almost always & $530(17)$ & $288(19)$ & $233(15)$ & $<.001$ & $185(14)$ & $163(22)$ & $182(22)$ & $<.001$ \\
\hline More than half the time & $251(8)$ & $139(9)$ & $104(7)$ & & $99(6)$ & $75(9)$ & 77 (9) & \\
\hline Less than half the time & $366(12)$ & $200(13)$ & $157(10)$ & & $142(10)$ & $119(13)$ & $105(13)$ & \\
\hline Never, almost never & $2,032(64)$ & $921(59)$ & $1,052(68)$ & & 731 (70) & $833(56)$ & $468(56)$ & \\
\hline
\end{tabular}


Table 4. Unsafe Behaviors and Crashes Among ATV-Exposed Students $(\mathrm{N}=4,320)$

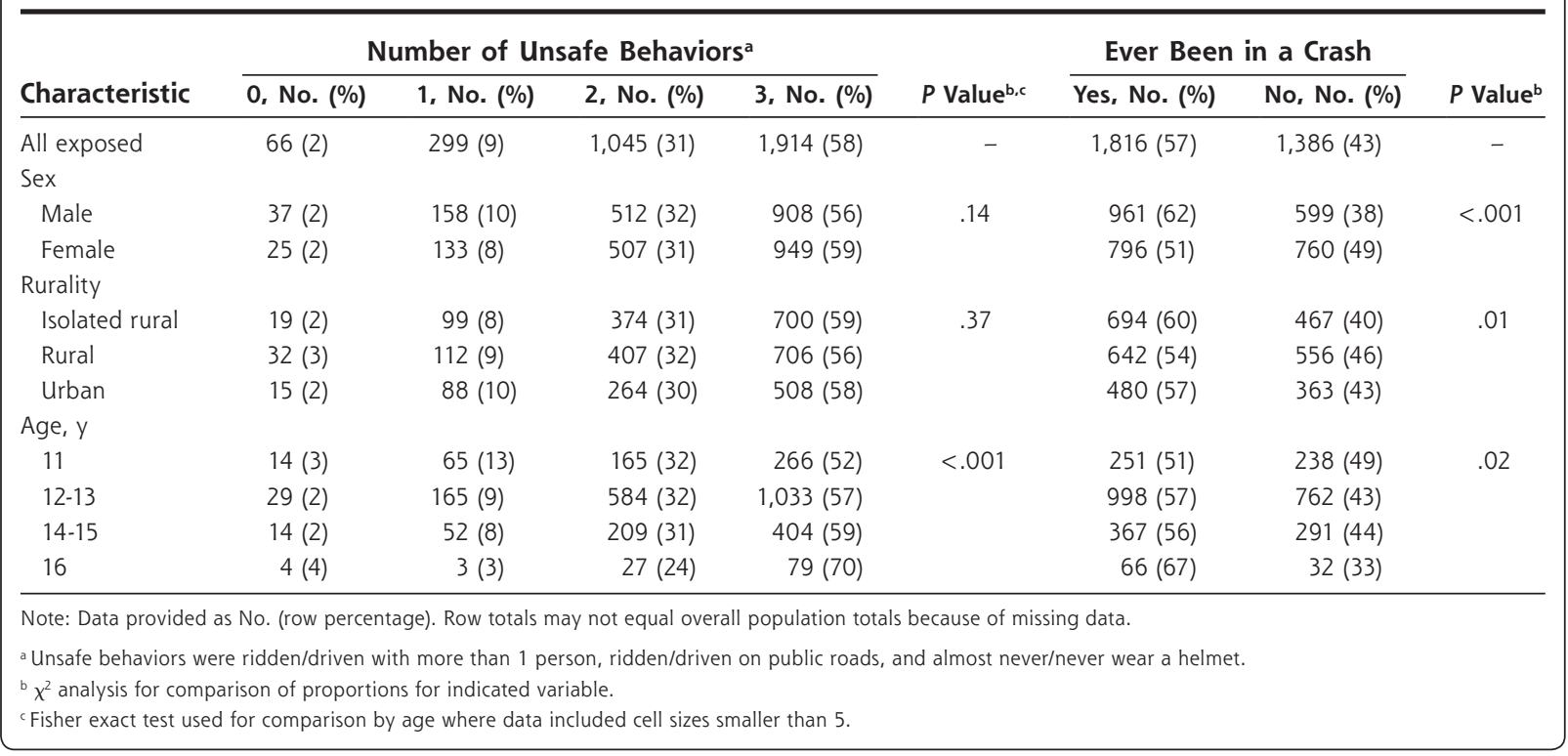

sengers but having been on the road ( $\mathrm{No}, \mathrm{Yes}$ ) were $77 \%$ more likely, and those reporting both behaviors (Yes, Yes) were more than 3 times more likely, to report having been in a crash than peers reporting neither behavior.

\section{DISCUSSION}

\section{Youth Exposure to ATVs}

Regardless of school rurality, at least three-fourths of students had previously ridden an $\mathrm{ATV}$, with almost $40 \%$ of those riding daily or weekly. Previous exposure studies reported similarly high percentages, including $97 \%$ of youth attending a national Future Farmers of America convention and 99\% of Connecticut children at agricultural fairs. ${ }^{711}$ Additionally, $44 \%$ of Illinois $4-\mathrm{H}$ club members surveyed had ridden an ATV in the previous 6 months, ${ }_{1}^{12}$ and 59\% of Arkansas youth at agricultural educational programs had ridden in the previous month. ${ }^{13}$ Taken together, these studies demonstrate that high adolescent ATV ridership is not limited to a single state or to more select youth populations. analysis.

\begin{tabular}{|c|c|c|c|c|}
\hline \multirow[b]{2}{*}{ Characteristic } & \multicolumn{4}{|c|}{ Exposure/Behavior } \\
\hline & $\begin{array}{c}\text { Rode on an ATV, } \\
\text { aOR }^{\text {a }}(95 \% \mathrm{Cl})\end{array}$ & $\begin{array}{c}\text { Rode/Drove } \\
\text { With >1 Person, } \\
\text { aOR }^{\text {a }}(95 \% \mathrm{Cl})\end{array}$ & $\begin{array}{c}\text { Rode on a } \\
\text { Public Road, } \\
\text { aOR }{ }^{\text {a }}(95 \% \text { Cl) }\end{array}$ & $\begin{array}{c}\text { Wear a } \\
\text { Helmet, } \\
\text { aOR }(95 \% \mathrm{Cl})\end{array}$ \\
\hline \multicolumn{5}{|l|}{ Sex } \\
\hline Male & $1.11(0.94-1.32)$ & $0.61(0.45-0.82)$ & $0.96(0.83-1.12)$ & $1.40(1.18-1.67)$ \\
\hline Female & 1.00 (ref) & 1.00 (ref) & 1.00 (ref) & 1.00 (ref) \\
\hline \multicolumn{5}{|l|}{ Age, y } \\
\hline 11 & 1.00 (ref) & 1.00 (ref) & 1.00 (ref) & 1.00 (ref) \\
\hline $12-13$ & $1.00(0.76-1.33)$ & $0.61(0.38-0.96)$ & $0.54(0.39-0.75)$ & $1.36(1.02-1.81)$ \\
\hline $14-15$ & $1.03(0.80-1.32)$ & $0.77(0.55-1.08)$ & $0.70(0.59-0.83)$ & $1.24(1.01-1.52)$ \\
\hline 16 & $1.39(1.02-1.89)$ & $2.74(1.11-6.74)$ & $1.11(0.73-1.69)$ & $0.76(0.51-1.12)$ \\
\hline \multicolumn{5}{|l|}{ Rurality } \\
\hline Isolated rural & $1.39(1.11-1.75)$ & $0.95(0.58-1.57)$ & $0.93(0.64-1.35)$ & $0.74(0.55-0.98)$ \\
\hline Rural & $0.90(0.70-1.17)$ & $0.79(0.47-1.34)$ & $0.78(0.57-1.08)$ & $0.61(0.41-0.90)$ \\
\hline Urban & 1.00 (ref) & 1.00 (ref) & 1.00 (ref) & 1.00 (ref) \\
\hline \multicolumn{5}{|l|}{ Riding frequency } \\
\hline Daily/weekly & NA & $2.03(1.51-2.74)$ & $5.64(3.91-8.13)$ & $0.94(0.80-1.10)$ \\
\hline Monthly & & $2.24(1.58-3.18)$ & $3.48(2.68-4.52)$ & $1.20(1.01-1.43)$ \\
\hline Yearly & & 1.00 (ref) & 1.00 (ref) & 1.00 (ref) \\
\hline
\end{tabular}

$\mathrm{NA}=$ not applicable; $\mathrm{aOR}=$ adjusted odds ratio; ref = reference category.

Note: Students with missing data for 1 or more of the variables in the model were not included in multivariable

a Controlled for all variables in the table. 


\begin{tabular}{|c|c|}
\hline Characteristic & $\begin{array}{c}\text { Experienced a Crash, } \\
\text { aOR }^{\mathrm{b}}(95 \% \mathrm{Cl})\end{array}$ \\
\hline \multicolumn{2}{|l|}{ Sex } \\
\hline Male & $1.61(1.36-1.91)$ \\
\hline Female & 1.00 (ref) \\
\hline \multicolumn{2}{|l|}{ Age, y } \\
\hline 11 & 1.00 (ref) \\
\hline $12-13$ & $0.89(0.68-1.15)$ \\
\hline $14-15$ & $1.12(0.88-1.42)$ \\
\hline 16 & $1.13(0.80-1.60)$ \\
\hline \multicolumn{2}{|l|}{ Riding frequency } \\
\hline Daily/weekly & $3.73(3.10-4.50)$ \\
\hline Monthly & $2.07(1.75-2.45)$ \\
\hline Yearly & 1.00 (ref) \\
\hline \multicolumn{2}{|l|}{ Rurality } \\
\hline Isolated rural & $1.26(0.78-2.05)$ \\
\hline Rural & $1.04(0.69-1.58)$ \\
\hline Urban & 1.00 (ref) \\
\hline \multicolumn{2}{|c|}{ Riding with $>1$ person/on road } \\
\hline No/no & 1.00 (ref) \\
\hline Yes/no & $1.30(0.84-2.20)$ \\
\hline No/yes & $1.77(1.14-2.74)$ \\
\hline Yes/yes & $3.24(2.09-5.04)$ \\
\hline
\end{tabular}

$\mathrm{aOR}=$ adjusted odds ratio; ref $=$ reference category.

a Students with missing data for 1 or more of the variables in the model were not included in multivariable analysis.

${ }^{b}$ Controlled for all variables in the table. Helmet use was not included in the model because it was not associated with crash risk and did not affect the aORs for other variables.

$88 \%$ rates previously reported..$^{711-13,16}$ In addition, more female students reported having ridden with multiple riders, which is consistent with previous reports that female youth were more likely to be injured passengers than male peers. ${ }^{8}$

From 1985 to 2009, 29\% of all ATV-related fatality victims in the United States were operators with passengers or were passengers themselves. ${ }^{17}$ Extra riders increase the likelihood of crashing by interfering with "active riding," that is, the body shifting required for maintaining the vehicle-rider center of gravity to prevent a rollover. Passengers can also interfere with steering or distract the driver, and are at higher risk of being ejected, often to the rear, which is more likely to result in a severe head injury. ${ }^{18}$

A previous study found that more than $95 \%$ of youth injured were on adult-size ATVs. ${ }^{5}$ Although almost all ATVs are specified as single-rider vehicles, seat lengths for adult-size vehicles vary considerably, with many long enough to accommodate multiple riders. ${ }^{19,20}$ This configuration likely encourages carrying passengers, especially among youth. ${ }^{4}$ Also, adult-size vehicles with longer seats often have seat fronts closer to the steering mechanism. ${ }^{20}$ This positioning may allow children to reach the handle grips and operate vehicles that are too large and fast for them to ride safely.

\section{Riding on the Road}

More than $80 \%$ of youth reported having ridden ATVs on public roads, despite lowa laws prohibiting such use, unless licensed and driving for work-related purposes. Previous studies found similarly high percentages of road use in response to general roadway questions and somewhat lower ones for riding on paved highways. ${ }^{11,16}$ Since 1998, fatal roadway crashes have increased at more than twice the rate of those off road ${ }_{1}^{17}$ and despite most riding being off road, ${ }^{6}$ more than $60 \%$ of fatal ATV crashes occur on roadways. ${ }^{17,21}$ Although collisions are a factor, two-thirds of roadway deaths do not involve other vehicles. ${ }^{17}$ Higher speed, coupled with the fact that ATVs are not designed for roadway use, may be major contributors to these fatalities.

\section{Helmet Use}

Less than one-fifth of students in our survey routinely wore a helmet, and the majority never or almost never did. This finding is consistent with studies of pediatric trauma patients showing rate of helmet use ranging from $16 \%$ to $28 \% .^{8,17,21,22}$ Female riders were less likely than male peers to wear helmets, possibly reflecting a previous observation that passengers have lower rates of helmet use than operators and that females are more likely to be passengers. ${ }^{8}$

Brain injuries are among the leading cause of death and disability from ATV crashes. ${ }^{23-25}$ They are more likely to occur on the roadway than off road, even when controlling for helmet use. ${ }^{8,17}$ This pattern may be due to forces in roadway crashes great enough to exceed the protective capacity of helmets. Brain injuries are also more likely among children younger than 16 years as compared with adults. ${ }^{8,17}$ Helmets are estimated to reduce the risk of fatal ATV-related head injuries by $40 \%$ and of nonfatal head injuries by $60 \%$ or more. ${ }^{8,17,25-27}$

\section{ATV Crashes}

Almost $60 \%$ of exposed students in our study reported having been in at least 1 crash in their lifetime. This value is similar to the $44 \%$ of children at Connecticut agricultural fairs and the $67 \%$ of Illinois 4 -H club members reporting having crashed. ${ }^{7,12}$ The likelihood and severity of ATV crashes have been shown to increase when multiple risk factors are involved. ${ }^{9}$ More than one-half of our exposed students reported engaging in all 3 unsafe behaviors.

\section{Anticipatory Guidance}

Primary care clinicians should be aware of possible ATV exposure, even among relatively young patients 
and nonfarm families. Children from urban localities could be exposed, particularly those from suburban acreages or who visit rural areas. Nonrural youth may be at even greater risk of crash and injury if they lack ATV riding experience. ${ }^{3}$

An American Academy of Pediatrics policy statement recommends that no child younger than 16 years of age ride an ATV. ${ }^{28}$ Although we support this recommendation, it is unlikely to be an effective message for many families. Primary care clinicians are in a unique position as a trusted source to offer ATV safety advice to patients and their families.

Medical organizations, including the American Academy of Family Physicians, promote injury prevention counseling in their health maintenance guidelines. ${ }^{29}$ Among anticipatory guidance interventions, safety counseling is supported by the best evidence. ${ }^{30-34}$ Although surveyed caregivers agreed that ATV injury prevention guidance is important to provide, only a minority performed this counseling. 35,36

Time constraints are always a concern as anticipatory guidance recommendations for health care visits are quite extensive. However, clinicians should determine whether their patients are exposed to ATVs and if so, should strongly consider injury prevention counseling. ATV use meets key criteria for guidance importance: high severity and frequency of injury, availability of environmental strategies to prevent injury, and evidence that the strategies are effective. ${ }^{37}$ Routine counseling by clinicians could greatly increase the number of adolescents receiving ATV safety education.

\section{Limitations}

Students may have experienced occasional difficulties with TurningPoint technology, either failing to answer a question or entering incorrect data. A total of 455 categorized as unexposed provided answers to subsequent behavior questions that suggested they did indeed ride ATVs. If all these students were included, the overall exposure rate would increase to $88 \%$. Thus, categorizing these students as unexposed may have underestimated exposure. A total of 114 students categorized as exposed also gave inconsistent answers, endorsing "Never been on an ATV" in response to 1 or more behavior questions. If all of these students were unexposed, then overall exposure would be reduced by $2 \%$ to $75 \%$. Although missing or inconsistent answers treated as missing could have affected final results, the large number surveyed likely reduced this possibility.

As with any self-report data, social desirability bias and peer-related effects could have affected results. Several factors decreased this likelihood: answers were obtained anonymously, timing prevented peer interac- tions during or between questions, and students may not have recognized behaviors as unsafe.

Student groups not evaluated included those home schooled and those with severe disabilities. In addition, lowa Department of Education data and RUCA coding indicate that lowa middle school students are $50 \%$ urban, 31\% rural, and 19\% isolated rural. This distribution compares with $27 \%, 39 \%$, and $34 \%$, respectively, for our sample. Our study's more rural population may limit its overall generalizability to the state. However, surveyed urban students reported exposure levels similar to their rural peers. Therefore, ATV exposure beyond our state's more rural communities should not be discounted.

Our findings may not be generalizable to all states, even those with student populations similar to Iowa's. However, high exposure rates were seen in previous studies of geographically diverse pediatric populations. ${ }^{7,11-13,16}$ Furthermore, lowa's pediatric ATV mortality rate is comparable to or lower than that of 21 other states, ${ }^{38}$ suggesting lowa is not unique regarding ATV use. Finally, all states, even those with large metropolitan areas, have rural and suburban populations. In fact, the states with the top 10 pediatric ATV fatality rates include California, Texas, Pennsylvania, Florida, and New York. ${ }^{1}$

\section{Conclusions}

A high proportion of students in our study reported being exposed to ATVs. Most practiced unsafe riding behaviors and had experienced at least 1 crash. These data illustrate the critical need for promoting safer behaviors among youth. Robust ATV injury prevention efforts are more widely needed, including training and well-enforced legislation. Primary care clinicians could play an important role in decreasing pediatric ATV-related injuries and deaths through routine anticipatory guidance.

To read or post commentaries in response to this article, see it online at http://www.annfammed.org/content/12/4/310.

Key words: all-terrain vehicle; injury prevention; adolescent behavior; rural; safety; helmet; prevention \& control; accidents

Submitted January 10, 2014; submitted, revised, April 7, 2014, accepted April 17, 2014.

Funding support: Support for this study was provided by a grant to the University of lowa Children's Hospital from Kohl's Cares, a program of Kohl's that supports kids' health and education initiatives nationwide.

Previous presentations: Preliminary findings of this study were presented at a number of venues including the ACEP Research Forum, October 2012, Denver, Colorado; the CPSC ATV Safety Summit, October 2012, Bethesda, Maryland; and the AAP National Conference $\&$ Exhibition, October 2012, New Orleans, Louisiana. 
Acknowledgments: We would like to acknowledge additional members of our ATV Injury Prevention Task Force, including Michele Lilienthal, Erin Northway, Lisa Roth, Lauren O’Donnell, Erika Billerbeck, Evelyn "Lou" Wolfe, Adam Collins, and Katrina Altenhofen for their help with this project.

\section{References}

1. US Consumer Product Safety Commission. 2011 annual report of all-terrain (ATV)-related deaths and injuries. http://www.cpsc.gov// Global/Research-and-Statistics/Injury-Statistics/atv2011.pdf. Accessed Oct 4, 2013.

2. Helmkamp JC, Aitken ME, Lawrence BA. ATV and bicycle deaths and associated costs in the United States, 2000-2005. Public Health Rep. 2009;124(3):409-418.

3. Rodgers GB, Adler P. Risk factors for all-terrain vehicle injuries: a national case-control study. Am J Epidemiol. 2001;153(11):1112-1118.

4. Aitken ME, Graham CJ, Killingsworth JB, Mullins SH, Parnell DN, Dick RM. All-terrain vehicle injury in children: strategies for prevention. Inj Prev. 2004;10(5):303-307.

5. Consumer Federation of America. All-terrain vehicle (ATV) safety crisis: America's children at risk. http://www.consumerfed.org/newsroom/studies\#2003. Accessed Oct 4, 2013.

6. General Accounting Office (GAO). All-terrain vehicles: how they are used, crashes, and sales of adult-sized vehicles for children's use. Report to Congressional Committees (GAO-10-418). 2010. http:// www.gao.gov/new.items/d10418.pdf. Accessed Oct 4, 2013.

7. Campbell BT, Kelliher KM, Borrup K, et al. All-terrain vehicle riding among youth: how do they fair? J Pediatr Surg. 2010;45(5):925-929.

8. Denning G, Jennissen C, Harland K, Ellis D, Buresh C. All-terrain vehicles (ATVs) on the road: a serious traffic safety and public health concern. Traffic Inj Prev. 2013;14(1):78-85.

9. Rodgers GB. Factors associated with the all-terrain vehicle mortality rate in the United States: an analysis of state-level data. Accid Anal Prev. 2008;40(2):725-732.

10. Shulruf B, Balemi A. Risk and preventive factors for fatalities in all-terrain vehicle accidents in New Zealand. Accid Anal Prev. 2010; 42(2):612-618.

11. Burgus SK, Madsen MD, Sanderson WT, Rautiainen RH. Youths operating all-terrain vehicles-implications for safety education. J Agromedicine. 2009;14(2):97-104.

12. Hafner JW, Hough SM, Getz MA, Whitehurst Y, Pearl RH. All-terrain vehicle safety and use patterns in central Illinois youth. J Rural Health. 2010;26(1):67-72.

13. Jones CS, Bleeker J. A comparison of ATV-related behaviors, exposures, and injuries between farm youth and nonfarm youth. J Rural Health. 2005;21(1):70-73.

14. Goldcamp EM, Myers J, Hendricks K, Layne L, Helmkamp J. Nonfatal all-terrain vehicle-related injuries to youths living on farms in the United States, 2001. J Rural Health. 2006;22(4):308-313.

15. Levenson M. All-terrain vehicle 2001 injury and exposure studies. Consumer Product Safety Commission Report. http://www.cpsc.gov/ library/foia/foia03/os/atvex2001.pdf. Accessed Oct 4, 2013.

16. Rodgers GB. The characteristics and use patterns of all-terrain vehicle drivers in the United States. Accid Anal Prev. 1999;31(4):409-419.

17. Denning GM, Harland KK, Ellis DG, Jennissen CA. More fatal allterrain vehicle crashes occur on the roadway than off: increased risktaking characterises roadway fatalities. Inj Prev. 2013;19(4):250-256.

18. Jennissen C, Denning $G$. The effect of passengers on all-terrain vehicle (ATV) crash mechanisms and injuries. US Consumer Product Safety Commission. ATV Safety Summit: Keeping Families Safe on ATVs, October 11-12, Bethesda, MD. 2012. http://www.slideshare.net/ USCPSC/atv-safety-summit-state-legislation-enforcement-the-effect-ofpassengers-on-atv-crash-mechanisms-injuries. Accessed Oct 4, 2013.
19. Jennissen CA, Miller NS, Tang K, Denning GM. An image-based method to measure all-terrain vehicle dimensions for engineering safety purposes. Inj Prev. 2014;20(2):115-120.

20. Jennissen C, Miller N, Tang K, Denning G. Optimising seat design for all-terrain vehicle injury prevention: wide variability illustrates need for evidence-based standardisation. Inj Prev. 2014;20(2):88-96.

21. Helmkamp JC. ATV-related deaths in West Virginia: 1990-2003. W V Med J. 2003;99(6):224-227.

22. Hall AJ, Bixler D, Helmkamp JC, Kraner JC, Kaplan JA. Fatal allterrain vehicle crashes: injury types and alcohol use. Am J Prev Med. 2009;36(4):311-316.

23. Brandenburg MA, Brown SJ, Archer P, Brandt EN Jr. All-terrain vehicle crash factors and associated injuries in patients presenting to a regional trauma center. J Trauma. 2007;63(5):994-999.

24. Bhutta ST, Greenberg SB, Fitch SJ, Parnell D. All-terrain vehicle injuries in children: injury patterns and prognostic implications. Pediatr Radiol. 2004;34(2):130-133.

25. Bowman SM, Aitken ME, Helmkamp JC, Maham SA, Graham CJ. Impact of helmets on injuries to riders of all-terrain vehicles. Inj Prev. 2009;15(1):3-7.

26. Merrigan TL, Wall PL, Smith HL, Janus TJ, Sidwell RA. The burden of unhelmeted and uninsured ATV drivers and passengers. Traffic Inj Prev. 2011;12(3):251-255.

27. Myers ML, Cole HP, Mazur JM. Cost effectiveness of wearing head protection on all-terrain vehicles. J Agromedicine. 2009;14(3):312-323.

28. American Academy of Pediatrics. All-terrain vehicle injury prevention: two-, three-, and four-wheeled unlicensed motor vehicles. Pediatrics. 2000;105(6):1352-1354.

29. Riley M, Locke AB, Skye EP; Association of American Family Physicians. Health maintenance in school-aged children: part II. Counseling recommendations. Am Fam Physician. 2011;83(6):689-694. http:// www.aafp.org/afp/2011/0315/p689.html. Accessed April 2014.

30. Nelson CS, Wissow LS, Cheng TL. Effectiveness of anticipatory guidance: recent developments. Curr Opin Pediatr. 2003;15(6):630-635.

31. Bass JL, Christoffel KK, Widome M, et al. Childhood injury prevention counseling in primary care settings: a critical review of the literature. Pediatrics. 1993;92(4):544-550.

32. Kelly RB. Effect of a brief physician intervention on seat belt use. J Fam Pract. 1987;24(6):630-632.

33. Chen J, Kresnow MJ, Simon TR, Dellinger A. Injury-prevention counseling and behavior among US children: results from the second Injury Control and Risk Survey. Pediatrics. 2007;119(4):e958-e965.

34. Stevens MM, Olson AL, Gaffney CA, Tosteson TD, Mott LA, Starr P. A pediatric, practice-based, randomized trial of drinking and smoking prevention and bicycle helmet, gun, and seatbelt safety promotion. Pediatrics. 2002;109(3):490-497.

35. Jennissen CA, Denning GM, Sweat S, Harland K, Buresh C. Allterrain vehicle injury prevention: healthcare providers' knowledge, attitudes, and the anticipatory guidance they provide. J Community Health. 2012;37(5):968-975.

36. Frascogna MN, King B, Lycans S, Nichols M, Monroe K. Assessing the knowledge of all-terrain vehicle safety for children among Alabama pediatricians. Pediatr Emerg Care. 2011;27(8):727-730.

37. Cohen LR, Runyan CW, Downs SM, Bowling JM. Pediatric injury prevention counseling priorities. Pediatrics. 1997;99(5):704-710.

38. Upperman JS, Shultz B, Gaines BA, et al. All-terrain vehicle rules and regulations: Impact on pediatric mortality. J Pediatr Surg. 2003; 38(9):1284-1286. 